\title{
Looked after children: education, school and unauthorised absence - perspectives from young people
}

\begin{abstract}
This paper reports the findings of a research project which explored why there are higher rates of unauthorised absence from school among Looked after Children (LAC) in Northern Ireland. Four young people who were currently looked after and also had a history of unauthorised absence from school participated in semi-structured, one to one interviews. Focus was placed on their perceptions of education, experiences of school and was factors contributed to their engagement in unauthorised absence from school. Interpretative Phenomenological Analysis conducted on the interview transcripts revealed that bullying, negative perceptions of teachers and lack of meaning to attend school were key issues identified. The role of teacher/pupil attachment and resilience measures are also discussed.
\end{abstract}

\author{
Volume 6 Issue I - 2016 \\ Emma O Neill, Tony Cassidy, O Connor \\ Bones U \\ Ulster University, UK
}

Correspondence: Tony Cassidy, Ulster University, Cromore
Road Coleraine Northern Ireland BT52 ISA, UK, Tel

4400000000000,Email t.cassidy@ulster.ac.uk

Received: April 26, 2016 | Published: June 13,2016

\section{Background}

Under the Children Act 1989 the term 'looked after children' (LAC) refers to children in the United Kingdom who are provided with substitute care either on a voluntary basis to assist parents or as a result of a court order. On the 31st of March 2012 there were approximately 2644 looked after children in Northern Ireland who were looked after continuously for a period of 12 months of which $74 \%$ were placed in foster care, $11 \%$ were placed with family members, $9 \%$ in residential care and $7 \%$ in other placements types. $52 \%$ of these children and young people were male and $48 \%$ female. $22 \%$ were aged $0-4,31 \%$ aged $5-11,28 \%$ aged $12-15$ and $18 \%$ aged 16-18 (DHSSPS, 2012). The majority of children who enter the care system have experienced abuse and/or neglect which can take the form of physical, emotional or sexual abuse. The effects of trauma during childhood or adolescence can have important and possibly long term consequences for a child's development and has been associated with neuro developmental difficulties, cognitive ability, educational performance, emotional dysfunction, belief in self-efficacy, insecure attachments and impaired social competences. ${ }^{1}$ Looked after children are also more likely to have come from disadvantaged backgrounds where a number of social/environmental risk factors are present. ${ }^{2}$ The educational attainment of LAC has been of concern for many decades $^{3-5}$ with a growing body of literature detailing the poor educational experiences and under achievement of LAC as well as the longer term impact that this can have, with these children growing up to be amongst the most vulnerable adults in society. ${ }^{6}$

A range of factors have been associated with the low educational achievement of LAC and have been proposed at least as partial explanations for poor educational outcomes. Some authors suggest that pre-care experiences and characteristics of looked after children may disadvantage them educationally with higher numbers of looked after children being excluded from school, having educational and behavioural difficulties including special educational needs, all of which are likely to affect their educational progress. ${ }^{7}$ While other research suggests that structural features of the care system including placement instability and the lower priority status given to education by social services, all contribute to a decreased ability to engage in education. ${ }^{8,9}$

While existing literature has gone to great lengths to understand why education for LAC is so problematic, the area of non-attendance at school including unauthorised absence or truancy remains largely under researched. Figures from the Department of Education Northern Ireland indicate that in the school year 2010/11 looked after pupils in post-primary schools show higher incidences of absence in comparison to their peers, more than half of which are unauthorised ${ }^{10}$ which suggests the need for further exploration of this issue.

Truancy from school can be serious and ultimately students with chronic absenteeism have fewer opportunities to learn, which impacts on their achievement potential with poor grades encouraging the cycle of poor attendance to continue. ${ }^{11}$ Worryingly truancy has been found to be highly correlated with high dropout rates from school, criminal activity, substance abuse and anti-social behaviour. ${ }^{12}$ Why children or young people do not attend school in this way has generated a range of research which suggests that truancy can be traced to personal, academic or social difficulties, chaotic family life, unsupportive school environments and lack of community support. ${ }^{11}$ Capps ${ }^{13}$ describes truants as seeing the world around them as unstable and confusing with many coming from dysfunctional, unstable and insecure homes. Many of the factors associated with young people who engage in unauthorised absence from school are also common in a looked after child's life which would suggest that this is a crucial area that requires in-depth research aimed at understanding why attendance at school is presenting as a problem for some looked after children more than others.

Lower rates of attendance at school among LAC have been identified as a key concern within this population. In particular higher levels of unauthorised absence are worrisome due to the association with at-risk behaviours and ultimately those who engage in truancy have fewer opportunities to learn. This study aimed to explore why some LAC engage in unauthorised absence from school by focusing on what this behaviour reveals about their perceptions of education, their experiences of the school environment and what factors contribute to their engagement in unauthorised absence from school.

\section{Method}

\section{Design}

As this was an exploratory study, a qualitative research methodology was employed using semi-structured, in-depth interviews as the primary source for data collection. Qualitative methodology was 
most appropriate in this case due as qualitative strategies intend not to impose preordained concepts. ${ }^{14}$

\section{Participants and Sampling Procedures}

Participant recruitment was facilitated by Voices of Young People in Care (VOYPIC) which is a charity that seeks to empower and enable young people with an experience of the care system to participate fully in the decisions affecting their lives. Criteria for this study were limited to those who were currently looked after by local authorities and had a history of unauthorised absence from school. In total 4 young people took part consisting of 2 males and 2 females, ranging from 14 to 17 years of age. 2 young people were currently attending some form of education provision while the other 2 had just recently finished their formal secondary educational provision.

\section{Ethics}

Ethical approval for this study was granted on 7th November 2011 by the University of Ulster Research and Ethics Committee.

\section{Analysis}

Each interview recording was transcribed verbatim. Due to the exploratory nature of the study, Interpretative Phenomenological Analysis (IPA) was chosen to analyse the content of the transcribed interviews. The main focus of IPA is to explore in depth how individuals make sense of their external environment and the meanings that particular experiences have for them. The key aim of the analysis is to try to understand the content and diversity that these meanings have. ${ }^{14}$

\section{Findings}

Initially each young person was asked if they could describe their experiences of attending school:

Bullying: Three young people described being bullied by their peers during the school day:

a. Participant 2a: ...when I was in first year to second year I got really badly bullied... These three participants also felt that the bullying they were experiencing was related to being in care:

b. Participant 2d: ...most people would go at least my ma and da want me just stuff like that there some of them would say my mum never wanted me from the start and just said I was a denied child stuff like that there...

Negative perception of teachers: All of the young people had negative views or experiences with teachers in school in a variety of ways:

a. Participant 2a: ...I didn't get on with many teachers...

b. Participant 2b: ...they think they've too much power cause they're a teacher they try and overdo it like...

School had no meaning: One young person felt that school had no meaning and that there was no point in going:

a. Participant 2b: ...I felt like it had no meaning to be there you see most of the stuff they tried to teach you was just stupid really stupid cause you see the outer world of work nothing to do with it half the stuff they learn you it's just stupid...I felt I knew more than what I had to go there for it was stupid...I just felt like I knew more than what school was teaching me they weren't teaching me the right kind of things you could say for what I wanted...Another young person wasn't interested in education: b. Participant 2d: ...I missed a lot when I was at school my education and I just wasn 't really into anything at high school I'd just ignore everything I didn't really pick anything up...

Young people were then asked if there had been anything that had helped them address the issues they had in relation to attending school.

Support from teachers: While all the young people expressed negative perceptions of teachers, two young people also described having support from some which was helpful:

a. Participant 2b: ...if you're on your own it's one by one learning you you'll learn more it's the way I look at it...there was only one or two teachers in there that knew me...I got some work done cause there wasn't many in that class that kind of proves it know what I mean...

Finally all of the young people were asked if there was anything they thought others such as teachers or social workers should know that would help them understand the difficulties young people in care experience in relation to education.

Teachers should get to know young people: One young person suggested that if teachers got to know pupils in care on a more personal level, that this would be helpful:

a. Participant 2b: ...try to get the teachers to know you more see when teachers know you more they would know the rest of the class you know you're going to get more help...

b. Another young person felt that teachers need to be sensitive to how a young person is feeling about being in care:

c. Participant 2a: ...I think they just need to keep an eye on how a person is feeling about being in care so if they're a bit upset about it don't mention it cause that's what I found...

Social workers should talk to young people: Two participants felt that social workers should talk more to the young people they work with about how they are feeling about going to school:

a. Participant 2b: ...don't be on their back ask talk to them first find out the best way for them to go back to school cause you see when social workers are pushing you to go back that's more reason for you not to go you know you're annoying them see like when social workers were on my back pushing me to go I purposely didn't go...

b. Participant 2d: ...just basically it's not all they think is going on they have to ask they have to ask them what they think they have to ask the children what's going on for them no one ever asked what was going on at school for me they just decided it was this it was that no one ever asked the child what was wrong for them...

\section{Discussion}

Difficulties reaching data saturation occurred as a result of limited availability of young people to take part. While suitable numbers of young people did express an interest in the study, their circumstances dictated that participation was not possible within the time frame available. This is was in relation to the frequent instability many LAC experience during their care journey as previously highlighted. However the experiences and views of the young people who did participate still offer valuable insights regarding the education of LAC and important lessons can be learned from them. Each young person describes a poor experience of the education system and school environment through both bullying by peers and a negative perception or experience of teachers. These experiences seem to have 
led them to disengage from their educational process, to lose interest in education and their unhappiness is expressed in their truancy. Three young people described bullying of a verbal nature and it has been well established that bullying continues to be a serious issue in all schools across Northern Ireland. Despite the implementation of antibullying policy in 2003, the most recent report carried out by the Department of Education Northern Ireland (DENI) found that there had been little evidence of change in the frequency of pupils being bullied, with $39 \%$ of year 6 pupils and $29 \%$ of year 9 pupils reported being bullied at school in the previous two month. ${ }^{15}$

LAC are at a disproportionate risk of being bullied for a number of reasons, such as the stigma of being in care, regular changes in schools due to placement changes, difficulty forming friendships or poor relationships skills as a result of attachment difficulties, inappropriate reactions to situations as a result of learned behaviours, a reluctance to make friends, low self-esteem, lack of role models and a heightened need for privacy. ${ }^{16}$ Professionals and caregivers who are involved in the care of LAC not only need to be aware of these issues but also need to be adept at supporting those who are experiencing bullying, by teaching them the coping skills they need in order to manage these incidents. Little research exists that specifically addresses bullying among LAC yet it is often identified as one issue facing these young people. Most recently a survey carried out by VOYPIC identified bullying among 106 care-experienced young people of which $21 \%$ reported having been bullied. Despite relatively low numbers of pupils who are also looked after, schools need to be aware of the high likelihood that bullying of these young people can occur so that they can implement anti-bullying policy as a preventative measure.

Interestingly the participants in this study viewed their teachers negatively yet they also identified that when they did have a positive relationship with a teacher they were better able to engage in their school work. This is an important point and can be linked to attachment theory. ${ }^{17}$ Children's attachment style with their parents can serve as a template for the relationships they have with others and with those who they engage with. In the school environment this affiliation between teacher and child is likely to mirror the attachment the child has with its parents or caregivers. ${ }^{18}$ As they engage in educational activities directed by their teacher, children use their teacher as a secure base with a growing range of research that supports the belief that children with secure attachments are more successful in education. ${ }^{19} \mathrm{O}$ 'Connor $\&$ McCartney ${ }^{18}$ found support for this assertion by demonstrating that pupils with insecure parental attachments also had insecure teacher attachments in three independent samples. Their study suggested that teachers were more likely to have difficulty connecting with students who had an insecure attachment style because these children had negative views of the teacher that diminished the attachment process. As a result insecure children were more likely to have problems in the educational context than securely attached children because secure children were more likely to establish a secure relationship with the teacher and view the teacher favourably that enabled them to have the confidence necessary to succeed and utilise the teacher as a secure base from which they could explore and engage in the academic and school environment.

More specifically research has shown that while teachers can have an important role in a child's development, the counselling relationships between teachers and students can lead to more positive attitudes towards and fewer absences from school, higher academic performance and greater self-concept. ${ }^{20}$ Whisler ${ }^{21}$ suggests that a child's positive experience with their teacher can help buffer the effects of negative self-perception while Eccles, et al., ${ }^{22}$ found that it is the quality of the child/teacher attachment that is associated with the child's academic motivation and attitude towards education and school.

By viewing the lives of looked after children from a risk and resilience perspective there are an overwhelming number of risk factors present, meaning that by the time these children become teenagers without counter-acting protective forces in place, the likelihood of them becoming vulnerable adults is high. ${ }^{23}$

Yet not all looked after children go on to be become vulnerable adults with growing numbers succeeding despite the odds. ${ }^{24}$ Gilligan $^{25}$ suggests that there is a lot to be learned from these children who do well in the presence of difficult family or home circumstances. He promotes the necessity of employing a resilience led approach in policy and practice when working with children in need and highlights five key points that are needed when understanding resilience in children facing adversity including

i. reducing the number of problems by using interventions that eliminate problems and build on strengths,

ii. pathways and turning points in development such as a positive experience that influences a child's trajectory,

iii. having a secure base from which they can explore the world around them,

iv. self-esteem or self-worth were a child has at least one positive relationship or success that can buffer the effects of other failures, and

v. a sense of self direction were a child has a sense of where their life is leading.

Jackson and Martin ${ }^{23}$ identified educational success as a crucial factor when determining adult life style and social inclusion among looked after children and recommended that it should be given a high priority status by public care authorities. In their study of people who had been in care they determined a number a variables that appeared to contribute to psychological well-being and educational success such as having stability and continuity in care, learning to read at an early age, receiving support and encouragement from a parent, foster care or other significant adult to continue into further education, having peers outside of care who also did well at school, having high levels of internal locus of control and intrinsic motivation, attending school regularly whilst also having a relationship with a significant adult who acted as a mentor offering consistent encouragement and support on a regular basis. The young people in this study actively recommend that teachers and social workers should get to know those who they work with better. They describe how these adults should take the time to know and understand what the circumstances of their young people are and that this isn't only relating to education and school but also other areas of their lives. Their perception that this would be helpful for others can also be viewed as seeking out a secure attachment with a teacher or other significant other. Awareness and promotion of this relationship by service providers could serve as one of the building blocks necessary for the development of resilience in the challenging circumstances in which they find themselves.

Increasingly schools are being explored as places were resilience can be promoted. Given the high numbers of children served by school and the amount of time children spend in the school environment, provides a reasonable logic. ${ }^{26}$ In relation to LAC, research indicates that school may be an alternative resource for helping recovery from trauma especially if the home environment remains a source of 
continued stress..$^{27}$ Rutter $^{28}$ suggests that the positive impact of school is most evident in those who are vulnerable and have limited access to other support systems, with growing numbers of studies concluding that positive educational experiences may contribute to resilience and recovery among vulnerable children and young people underlining that these experiences also include social relationships as well as academic achievement. School can also be an appropriate place for resilience promoting interventions with school based programmes aimed at either the whole school or for specific groups such as LAC, that aim to develop emotional literacy and competence, emotional regulation, empathy, positive thinking and problem solving abilities.

Much can be learned from those with an experience of the care system, who manage to succeed in the face of adversity, much more attention needs to be given to the lessons that can be learned from young people struggling in the education system. The young people in this study were in many ways failed by those around them because they either didn't ask them what was happening in their lives or they didn't listen to what they had to say. They recommend that those involved in the care of LAC should talk with young people and via this report are asking for others to engage with them so that they can find ways to engage with education. Despite many publications seeking to understand the issues LAC face in relation to education, how can these young people be helped if no-one is really listening?

\section{Acknowledgments}

None.

\section{Conflicts of interest}

Author declares there are no conflicts of interest.

\section{Funding}

None.

\section{References}

1. Turney D, Tanner K. What do we know about child neglect? A critical review of the literature and its application to social work practice. Child and Family Social Work . 2003;8(1):25-34.

2. Department for Children, Schools and Families. Children Looked After (Including Adoptions and Care Leavers) Year Ending 31 March 2009. DfES, National Statistics, London. 2008.

3. Pringle MK. Deprivation and Education. Longman, London. 1965.

4. Jackson S. The education of Children in Care. Bristol Papers in Applied Social Studies No. 1. Adoption \& Fostering . 1987;12(4):6-11.

5. Jackson S. Educating children in residential and foster care: An overview. Oxford Review of Education. 1994;20:267-280.

6. McClung M, Gayle V. Exploring the care effects of multiple factors on the educational achievement of children looked after at home and away from home: an investigation of two Scottish local authorities. Child and Family Social Work. 2010;15(4):409-431.

7. Harker RM, Dobel-Ober D, Lawrence J, et al. Who Takes Care of Education? Looked after children's perceptions of support for educational progress. Child and Family Social Work. 2003;8(2):89-100.

8. Maxwell D, Sodha S, Stanley K. An asset account for looked after children. Institute for Public Policy Research, London. 2006.
9. Berridge D. Theory and explanation in child welfare: education and looked-after children. Child and Family Social Work . 2007;12(1):1-10.

10. Department of Education Northern Ireland. Attendance at grant-aided primary, post primary and special schools 2010-11. Northern Ireland 2012 .

11. McCray ED. It's 10am: Do you know where your children are? The persisting issue of school truancy. Intervention in School and Clinic. 2006;42(1):30-33.

12. Garry EM. Truancy: First step to a lifetime of problems. Juvenile Justice Bulletin . 1996;1-7.

13. Capps WR. The new face of truancy. School Administrator. 2003;60(4):34.

14. Smith JA. Qualitative Psychology: A Practical Guide to Research Methods. Sage Publications, London. 2003.

15. RSM McClure Watters. The Nature and Extent of Bullying in Northern Ireland Schools. Department of Education Northern Ireland. 2011.

16. Rao V, Simkiss D. Bullying in schools A survey of the experience of looked after children. Adoption and Fostering. 2007;31(3):49-57.

17. Bowlby J. The making and breaking of affectional bonds: Aetiology and psychopathology in the light of attachment theory. Br J Psychiatry. 1977;130:201-210.

18. O’Conner E, McCartney K. Testing associations between young children's relationships with mothers and teachers. Journal of Educational Psychology. 2006;98(1):87-98.

19. Pianta RC, Stuhlman MW. Teacher-child relationships and children's success in the first years of school. School Psychology Review. 2004;33(3):444-458.

20. Learner DG, Kruger LJ. Attachment, self-concept and academic motivation in high-school students. Am J Orthopsychiatry. 1997;67(3):485-492.

21. Whisler JS. The impact of teacher relationships and interactions on self-development and motivation. Journal of Experimental Education. 1991;60(1):15-30.

22. Eccles JS, Midgley C, Wigfield A, et al. Development during adolescence: The impact of stage-environment tit on young adolescents' experiences in schools and families. American Psychologist. 1993;48:90-101.

23. Jackson S, Martin PY. Surviving the care system: education and resilience. J Adoles. 1998;21(5):569-583.

24. Martin PY, Jackson S. Educational success for children in public care: advice from a group of high achievers. Child and Family Social Work. 2002;7(2):121-130.

25. Gilligan R. Adversity, young people and resilience: the protective value of positive school and spare time experience. Children and Society. 2000;14(1):37-47.

26. Brooks JE. Strengthening resilience in children and youths: maximizing opportunities through schools. Children and Schools. 2006;28(2):69-76.

27. Gilligan R. Adversity, resilience and the educational progress of young people in public care. Emotional and Behavioural Difficulties. 2007;12(2):135-145.

28. Rutter M. Pathways from childhood to adult life: the role of schooling. Pastoral Care in Education. 1991;9(3):3-10. 